\title{
A case of unusually located left ventricular myxoma: myxoma attached to the chordae tendinea of the mitral valve
}

\author{
Bugra Ozkan • Durmus Yildiray Sahin • \\ Mevlut Koc • Onur Kadir Uysal · Kamuran Tekin • \\ Murat Cayli
}

Received: 12 May 2011/Revised: 10 September 2011/Accepted: 13 September 2011/Published online: 20 October 2011

(C) The Author(s) 2011. This article is published with open access at Springerlink.com

\section{Introduction}

Myxomas are the most common type of benign cardiac tumors, which constitute about $30 \%$ of all primary cardiac tumors [1]. They are typically located in the fossa ovalis of the interatrial septum; however, valvular placement is very rarely seen [2].

\section{Case}

A 32-year-old male patient was admitted to our clinic with complaints of exertional chest pain and shortness of breath. His blood pressure was $120 / 70 \mathrm{mmHg}$ and his heart rate was $80 \mathrm{bpm}$. In the physical examination, Grade II/IV mid-diastolic murmur was noted at the cardiac apex with a harsh S1. His electrocardiogram was within normal limits. In transthoracic echocardiography, a mobile, heterogeneous mass was seen with a stalk in the left ventricle attached to the mitral valve (Fig. 1). For further evaluation, transesophageal echocardiography was performed. A $1.5 \times 3.2-\mathrm{cm}$ mass, attached to the chordae tendinea of mitral the valve with a thin pedicle, was observed (Fig. 2). Because the patient had a strong family history of coronary artery disease, he underwent coronary

B. Ozkan $(\bowtie) \cdot$ D. Y. Sahin · M. Koc .

O. K. Uysal · K. Tekin · M. Cayli

Department of Cardiology, Adana Numune Education and

Research Hospital, Adana, Turkey

e-mail: bugraozkan@yahoo.com angiography, which revealed normal coronary arteries. Surgery was scheduled for the removal of the mass. The patient underwent median sternotomy and cardiopulmonary bypass under general anesthesia. A gelatinous, polypoid, and lobulated mass attached to the chordae tendinea of the mitral valve posterior leaflet was observed and resected carefully, preserving the mitral valve structure. The postoperational echocardiography revealed a mild mitral regurgitation with no residual mass. Histopathological examination confirmed the diagnosis of myxoma. In the following third and sixth months, control transthoracic echocardiography was performed and evaluated as normal. Annual echocardiographic examination was scheduled for follow up.

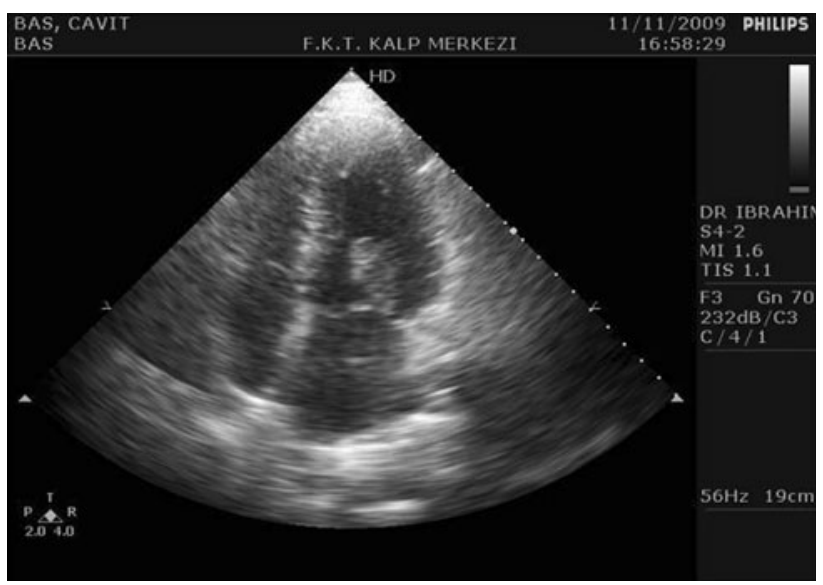

Fig. 1 Echocardiography in the apical four-chamber view showing free mobility of the myxoma attached to a chordae 


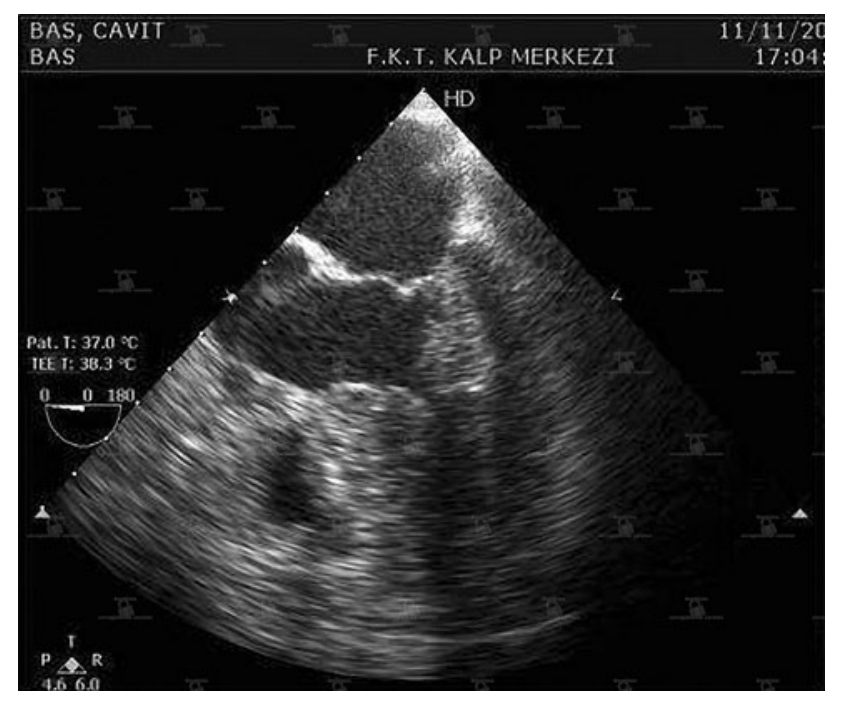

Fig. 2 Transesophageal echocardiogram demonstrated a large mass in the left ventricular cavity attached to a single chordae of the posterior leaflet of the mitral valve

Conflict of interest Our manuscript has no conflict of interest.
Open Access This article is distributed under the terms of the Creative Commons Attribution Noncommercial License which permits any noncommercial use, distribution, and reproduction in any medium, provided the original author(s) and source are credited.

\section{References}

1. Meng Q, Lai H, Lima J, et al. Echocardiographic and pathologic characteristics of primary cardiac tumors: a study of 149 cases. Int J Cardiol. 2002;84:69-75.

2. Dijkhuizen T, van den Berg E, Molenaar WM, et al. Rearrangements involving 12p12 in two cases of cardiac myxoma. Cancer Genet Cytogenet. 1995;82(2):161-2. 